\title{
Campylobacter: A foodborne pathogen with emerging antimicrobial resistance
}

Amritanjali Kiran ${ }^{1}$, Maria Josefina Ruiz Alvarez², Khine Swe Swe Han ${ }^{3}$, Abishek Kumar B 4, ${ }^{*}$, Dipanjan Chakraborty ${ }^{5}$, Lawrence Mugisha ${ }^{6}$, Hana Elbadawi ${ }^{7}$, Yara Khalaf $^{8}$, Aparna Panicker ${ }^{9}$, Sajini Souda ${ }^{10}$, Maarten B.M. van Dongen ${ }^{11, *}$

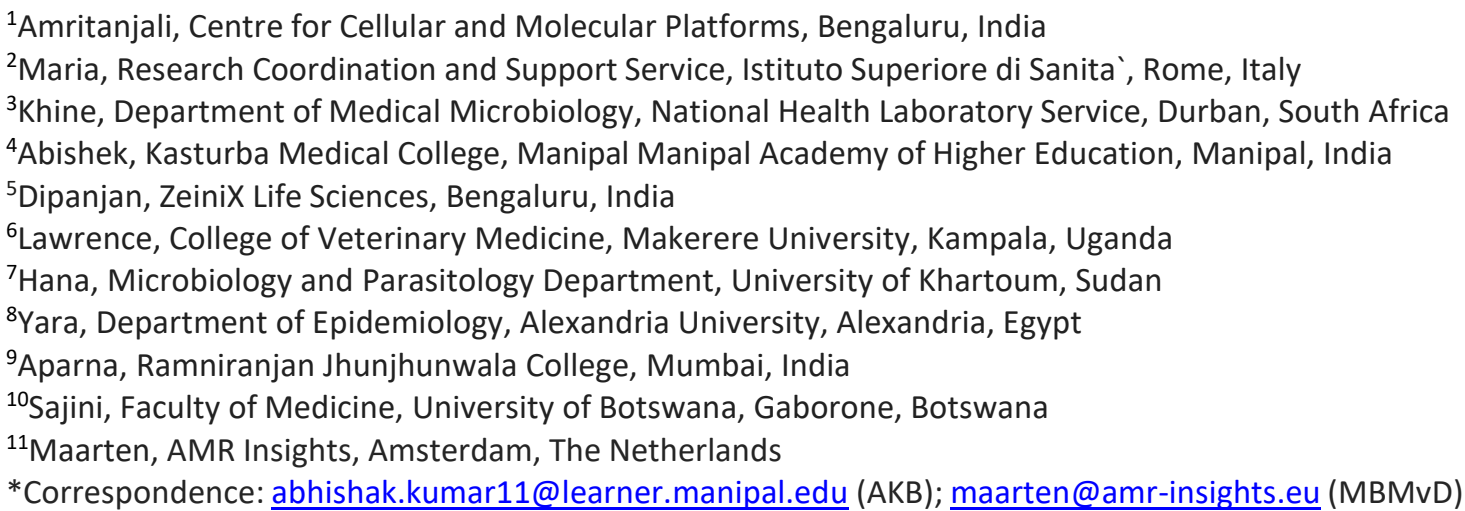

The first author and all co-authors are members of the global Network of AMR Insights Ambassadors. The AMR Insights Ambassador Network consists of an integrated global and cross-professional community discussing, devising, and driving actions to combat AMR. The Network aims to inspire, connect, and empower the Ambassadors to take individual and collective actions to curb AMR. For more information about this network: www.amrinsights.eu/about-us/ambassadors

\begin{abstract}
Campylobacter is one of the major foodborne pathogens of concern in its growing trend of antimicrobial resistance. $C$. jejuni and $C$. coli are the major causative agents, with $C$. jejuni contributing to most of the cases in approximately $90 \%$ of the world. Infection is transmitted to humans due to the consumption of contaminated food and water. Campylobacteriosis caused by $C$. jejuni is commonly presented with severe diarrhea, abdominal pain, fever, headache, nausea, and vomiting with some extreme cases resulting in Guillain-Barré syndrome (GBS) and acute flaccid paralysis. Symptoms are severe in cases of children below 5 years, the elderly, and individuals who are immunocompromised. The infection is usually sporadic, and self-limiting and thus does not require antibiotics for treatment. Still, the antimicrobial resistance
\end{abstract}


Campylobacter is a major concern because of the transmission of resistance from animal sources to humans. This review highlights the recent epidemiology, geographical impact, resistance mechanisms, spread of Campylobacter spp., and the strategies to control the transmission of Campylobacter from veterinary sources and its antimicrobial resistance.

Keywords: Campylobacter, antimicrobial resistance, foodborne pathogen, animal source.

\section{Epidemiology of Campylobacter}

Annually, approximately 0.8 million cases occur in the United States of America alone, with the incidence of high-income countries being 4.4-9.3 per 1000 population(Havelaar et al., 2015). In 2014, Europe reported a total of 240,379 confirmed cases from a total of 28 countries - an increase of $13 \%$ from the previous year.(Campylobacteriosis - Annual Epidemiological Report 2016 [2014 Data], n.d.) In the Oceania regions, Campylobacteriosis was the most notified foodborne infection in Australia during 2010, with 16,968 cases.(Kaakoush et al., 2015)

Although surveillance data from developing countries are limited, Campylobacteriosis is notedto be endemic in certain parts of Africa, Asia, and the Middle East, especially in children under 2 years of age, who often have repeated and chronic infections.(Kaakoush et al., 2015)(Pascoeet al., 2020) Campylobacter infections rarely cause mortality, with occasional deaths occurring in the elderly, immunocompromised, or pediatric population.(Kaakoush et al., 2015)(Havelaar et al., 2015)

\section{The geographical impact of Campylobacter}

Campylobacter infection is transmitted from the zoonotic origin and studies reported its presencein domestic as well as wild birds and animals in different parts of the world.(Hald et al., 2016)(Truccollo et al., 2021)Spiking of infection rate around summer has been reported in Nordic countries like Sweden and Norway(Kuhn et al., 2020). However, the infection reports of Australia did not indicate the influence of the summer season on the number of reported infections(Bi et al., 2008). Weather and temperature influence on Campylobacteriosis is also not defined and is considered to be indirect as countries with a high-temperature range of 18.45 ${ }^{\circ} \mathrm{C}\left(65.21^{\circ} \mathrm{F}\right)$ to $36.9^{\circ} \mathrm{C}\left(98.4^{\circ} \mathrm{F}\right)$ like Nigeria as well as countries with a low average temperature between $10^{\circ}$ to $15^{\circ} \mathrm{C}\left(50-59^{\circ} \mathrm{F}\right)$ like Iceland have reported cases of Campylobacteriosis 
indicating no correlation of temperature does on the growth and spread of the Campylobacter species in different regions(Callicott et al., 2008). There are not many studies reporting the geographical, climate, and temperature impact of Campylobacter infections, and the available studies do not prove any significant correlation of geographical impact on the Campylobacter infection(Gwimi et al., 2015).

\section{Resistance mechanism in the context of food poisoning of Campylobacter}

The dynamic adaptation of Campylobacter is attributed to its genetic flexibility, which benefits the organism with rapid evolution. The innate error reading mechanisms, vulnerable genome for mutation, and cells exposed for receiving horizontal genes, collectively promote Campylobacter with positive selection for adaptability to colonize hosts and to develop antimicrobial resistance. (Costa \& Iraola, 2019) As the bacteria passes through various host communities, the cost of bacterial fitness increases, and the Campylobacter infections in humans are commonly associated with antibiotic resistance(Costa \& Iraola, 2019). Study of diarrheal cases caused by $C$. jejuni to determine the antibiogram associated with molecular resistance mechanism shows that resistance to fluoroquinolones (55.8\%) and tetracyclines (49.7\%) was high(Elhadidy et al., 2020). Concerning the past studies, resistance to ciprofloxacin and tetracycline had exponentially increased(Wieczorek et al., 2018) with a growing trend of treatment complications in infants as they are commonly used antibiotics for treating non-self-limiting diarrhea and systemic Campylobacteriosis.(Schiaffino et al., 2019)(Dai et al., 2020) DNA gyrase mutation C257T in gyrA gene and tetracycline resistance gene tetO, was detected in the majority of the clinical isolates, but few of them also seem to have developed resistance physiologically. The teto gene contributing resistance to tetracycline was found to be horizontally transferred from poultry sources. (Avrain et al., 2004)Macrolideresistance in the diarrhoeal isolates resulted in $2 \%$ acquired by ermB coding for efflux pump, $r p / D$, and $r p / V$ genes in 23 s rRNA mutation of 50 S ribosomal subunit resistance genes.(Elhadidyet al., 2020) This brings a future insight to explore physiologically resistant populations of Campylobacter spp in human infections. Thermotolerant communities of Campylobacter were encountered in the poultry and bovine meat with higher resistance to antibiotics.(Di Giannatale et al., 2019) As a gastrointestinal pathogen, thermotolerance and other physiological resistance to acids or salts is required for the survival instincts of the organism to 
the flow between hosts through the food chain. Such tolerance mechanism may be attributed to theresistance to antibiotics phenotypically. Antibiotic tolerance mechanism is common in Pseudomonas aeruginosa and it leads to treatment failure in chronic infections(Abishek et al., 2021). Further studies are required in the antibiotic tolerance of Campylobacter.

\section{Morphophysiological Characteristics of Campylobacter}

Campylobacter bacteria are small, Gram-negative, non-spore-forming that exist as either curved or spiral-shaped rods which are oxygen-sensitive, highly mobile, and prefer to grow under micro-aerobic conditions. They attain a polar flagellum at one or both ends of the cell, are catalase and oxidase-positive, and urease negative. They are fastidious organisms that belong to a distinct group designated rRNA superfamily $\mathrm{VI}$ and have been reported to change into coccoid forms on exposure to adverse conditions, especially oxidation. In general, these bacteria are fragile and easily destroyed by heat, acidity, desiccation, and disinfectants.

\section{Virulence factors of Campylobacter}

Enteric Campylobacters are predicted to express several putative virulence factors when colonizing the intestines, allowing for their survival against food processing and resistance to physiological stress.(Bolton, 2015) The different virulence-related mechanisms include invasive properties (facilitating binding and entry into host cells), bacterial adherence to the intestinal mucosa, oxidative stress defense, heat shock, toxin production (e.g., cytotoxins and cytolethal distending toxin, causing cell death), iron acquisition (for nutrition), and its ability to remain in a viable, but non-culturable (VBNC) state.(Backert et al., 2013) Other Campylobacter virulence factors entail secretion of some sets of proteins, translocation capabilities, chemotaxis (to traverse chemical gradients), and flagella-mediated motility (enabling movement into the mucous layer). (Biswas et al., 2011)

\section{Impact of antimicrobial Resistance in Campylobacter}

There is a sharp increase in the resistance of Campylobacter to fluoroquinolones, putting into consideration that there is an alarming increase in the fluoroquinolone's resistance on a global level. This has led to limiting the use of fluoroquinolone as a treatment option for human infection, yet there is relatively low resistance to macrolides.(Ruiz-Palacios, 2007) Campylobacteriosis is a foodborne zoonotic disease; hence the presence of resistant strains in the food chain will have an impact on human infection. (Wieczorek et al., 2018) Different 
studies have stated that being infected with quinolone or erythromycin- 
resistant strains of Campylobacter species are associated with increase adverse drug reactions when compared with susceptible species as well as long duration of illness, which will also lead to narrowing the options for treating the cases that need antibiotics and increasing in treatment failure for diarrheal disease.(Ruiz-Palacios, 2007)

It is important to tackle the rising Campylobacter antimicrobial resistance, especially when dealing with high-risk populations such as the elderly or immunocompromised. This is because ofthe high risk of bacteremia and other complications leading to the use of antibiotics for treatment. In some cases, they can even disseminate in the periphery and cause profound disease.(Yang et al., 2019)

Campylobacter bacteremia has a very low detection rate, which in Europe accounts for less than $1 \%$ of total patients with gastroenteritis. This can be attributed to many factors such as lack of diagnosis and avoiding blood cultures routines for gastroenteritis patients. (Mearelli et al., 2017). It is very serious in patients with immunodeficiency (mainly AIDS), gammaglobulinemia, diabetes mellitus, cirrhosis, and complement system disease, as well as in those who are receiving corticosteroid therapy. Campylobacter jejuni is the most isolated species among other Campylobacter spp. causing sepsis, a fatal septic shock with Multiple Organ Failure. Campylobacter jejuni case report was identified, where the culture did show resistance to cephalothin, amoxicillin, amoxicillin/clavulanate, aminoglycosides, erythromycin, and pefloxacin.(Meyrieux et al., 1996) Another case was presented with a septic shock with multi-organ failure due to fluoroquinolone-resistant Campylobacter jejuni where two blood cultures yielded Campylobacter jejuni resistant to fluoroquinolones and sensitive to macrolides. (Mearelli et al., 2017)Prevention and controlling measures to antimicrobial resistance are essentially needed to help to curb antimicrobial resistance which will have a positive impact on managing Campylobacter cases.

\section{Sources of Campylobacter}

The colonization of different animal reservoirs by Campylobacter poses an important risk for humans through the shedding of the pathogen in livestock waste and contamination of water sources, the environment, and food.(Igwaran and Okoh, 2019) Human infections may therefore be acquired via infected animals and their food products through various means including consumption of unpasteurized milk, untreated water, or undercooked poultry or 
red meat. Fecal contamination of meats, particularly of poultry origin, often occurs during slaughtering, resulting in cross-contaminated food products. Campylobacter infections can also be acquired through direct contact with infected pets within the family environment.(Campylobacter Infections: Background, Pathophysiology, Epidemiology, n.d.)(Asuming-Bediako et al., 2019)(Igwaran and Okoh, 2019) According to literature (20072013), a majority of Campylobacter outbreak cases were associated with poultry products (50-70\%) and contaminated water, with colonized animals developing a lifelong carrier state.

\section{Transmission of Campylobacter}

Campylobacteriosis is a zoonotic disease, transmitted from animals or animal products to humans. The organism Campylobacter colonizes the gastrointestinal tract and reproductive tract of a wide variety of wild and domestic food animals including poultry, cattle, pigs, sheep, dogs and cats, ostriches, deer, and shellfish.(Liu et al., 2018)(Buchanan et al., 2017) The main route of transmission is through ingestion of contaminated food, water, or milk and consumption of eggs, raw or undercooked meat that become contaminated during slaughtering. Food, especially salads, can be cross-contaminated from raw meat when using the same cutting board, knives, and utensils. (Information for Health Professionals I Campylobacter / CDC, n.d.)(Newell and Fearnley, 2003). Consumption of contaminated raw milk, unpasteurized milk, or failure of milk pasteurization also is a source of transmission of Campylobacter infection. (Kenyon et al., 2020)(Kaakoush et al., 2015) 


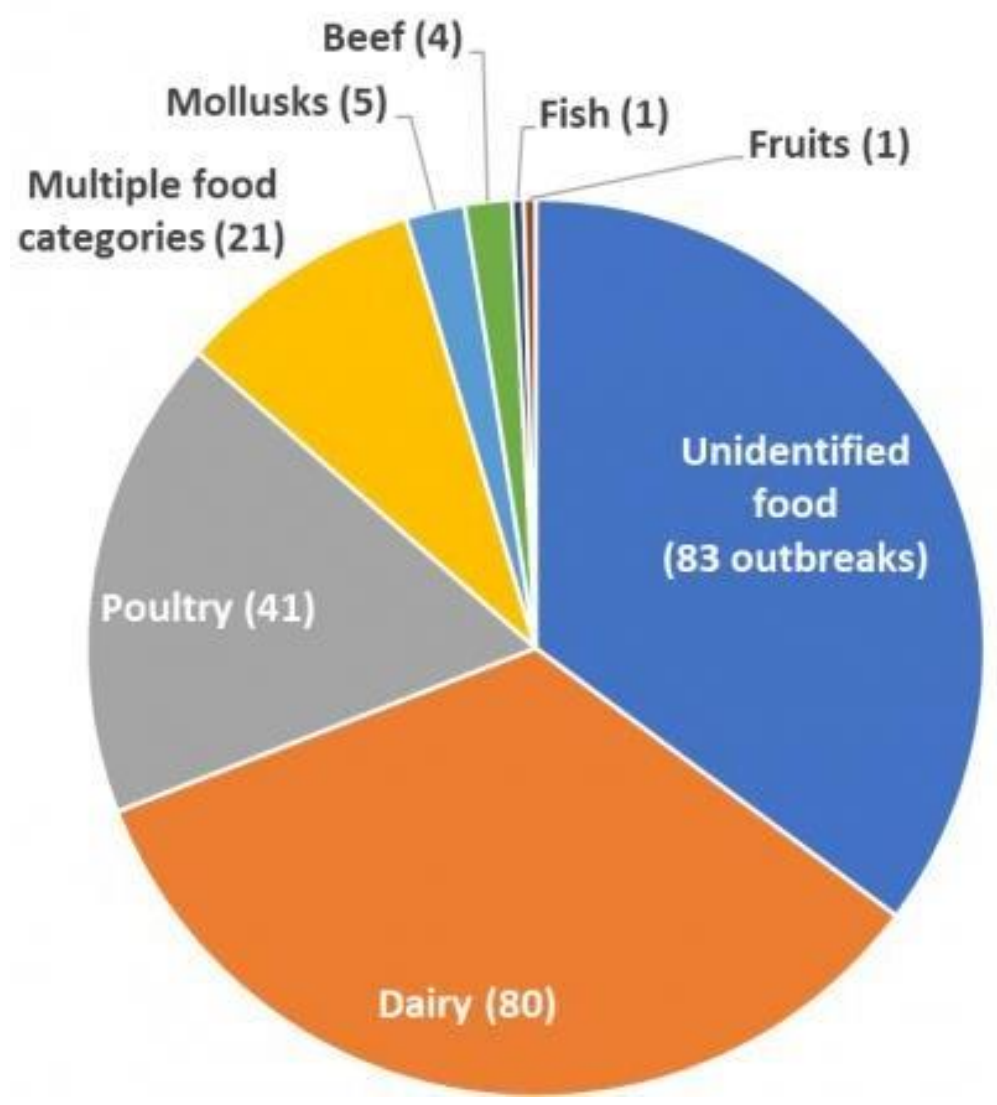

Fig 1. Outbreaks caused in the United States by Campylobacter, by food category, 20102017(https://www.cdc.gov/Campylobacter/technical.html

\section{Clinical Manifestations of Campylobacter Infection in Humans}

Ingestion of 500-800 bacteria can result in human disease. However, there are reports of 100 Campylobacter cells or less causing infections in humans.(Frirdich et al., 2017) Acute diarrhea (including traveler's diarrhea and children's diarrhea) is the major infection caused by Campylobacter. Watery or bloody diarrhea, accompanied by fever, stomach cramps, abdominal pain, nausea, and vomiting is most common. Bloating, headache, and muscle pain may also occur in some patients. Symptoms of Campylobacteriosis usually begintwo to five days after exposure, but it can also be as little as one day or in ten days. These symptoms generally last three to six days, although occasionally they may last longer.(Gharstet al., 2013)(Scallan et al., 2015) Campylobacter has been reported as one of the pathogens responsible for benign convulsions with mild gastroenteritis (BCWG), especially in summer and autumn.(Chen et al., 2019) Childhood Campylobacter has been reported to manifests as a single gastroenteritis complication in a previously healthy young child or as recurrent 
episodes in an older, immune-compromised child, usually without gastrointestinal symptoms.(Bi et al., 2008)

\section{Current guidelines to tackle Campylobacter and its drawbacks.}

The epidemiology of Campylobacteriosis revealed an increasingly important role for Campylobacter infection in public health, not only for the prevalence but also for the high level of resistance in humans. In humans, Campylobacter spp. was the $50 \%$ of all reports alone $(220,682$ confirmed cases) on the last annual report of the European Food Safety Authority (EFSA) and the European Centre for Disease prevention and control (ECDC) on zoonoses, zoonotic agents and on epidemic outbreaks of transmitted diseases food, relating to data collected in 2019, from 36 European countries (28 EU Member States and 8 nonmembers)(Food Safety Authority et al., 2021). The most effective strategies are based on the interactive epidemiological information from surveillance systems. One example of them is The Foodborne Diseases Active Surveillance Network (FoodNet) for the identification of food infections caused by Campylobacter and other pathogens FoodNet monitors over 300 laboratories in various US states and approximately 25 million people. Briefly, the lines of control are established following the last Regulation (EU) 2017/1495 of August 23, 2017, that amends the Regulation (No. 273/2005) and the EFSA studies. The 2011 EFSA opinion on Campylobacter was updated using more recent scientific data and reviewed the control options for Campylobacter in broilers at primary production. The guidelines of control of Campylobacter are divided into three main pillars, farms, food industry, and distribution. In the food industry the important steps are the sanitization considering the sensitivity to biocides (for a reduction> $5 \log \mathrm{CFU} / \mathrm{mL}$ of Campylobacter jejuni); the capacity of forming mono biofilms and multispecies, both in aerobic conditions as anaerobic; the greater resistance to environmental conditions and the increased cell transfer capacity (Seliwiorstow, $T$ 2016). Thesolution is neither simple nor easy. We should dedicate effort to harmonize methodologies of control all along with the chain food and to push the research and exchange of information (fig.2). The most important challenges are the standardization of validation measures, biocontrol methodologies in the poultry sector (principal source mediating Campylobacter transmissionto humans), including a harder promotion of innovation and efficacy skills among all ecosystem actors. All actions need to go in parallel with policies for control and notification 
of contamination, and at the same time to increase the consumer's protection.(Kaakoush et al., 2015)

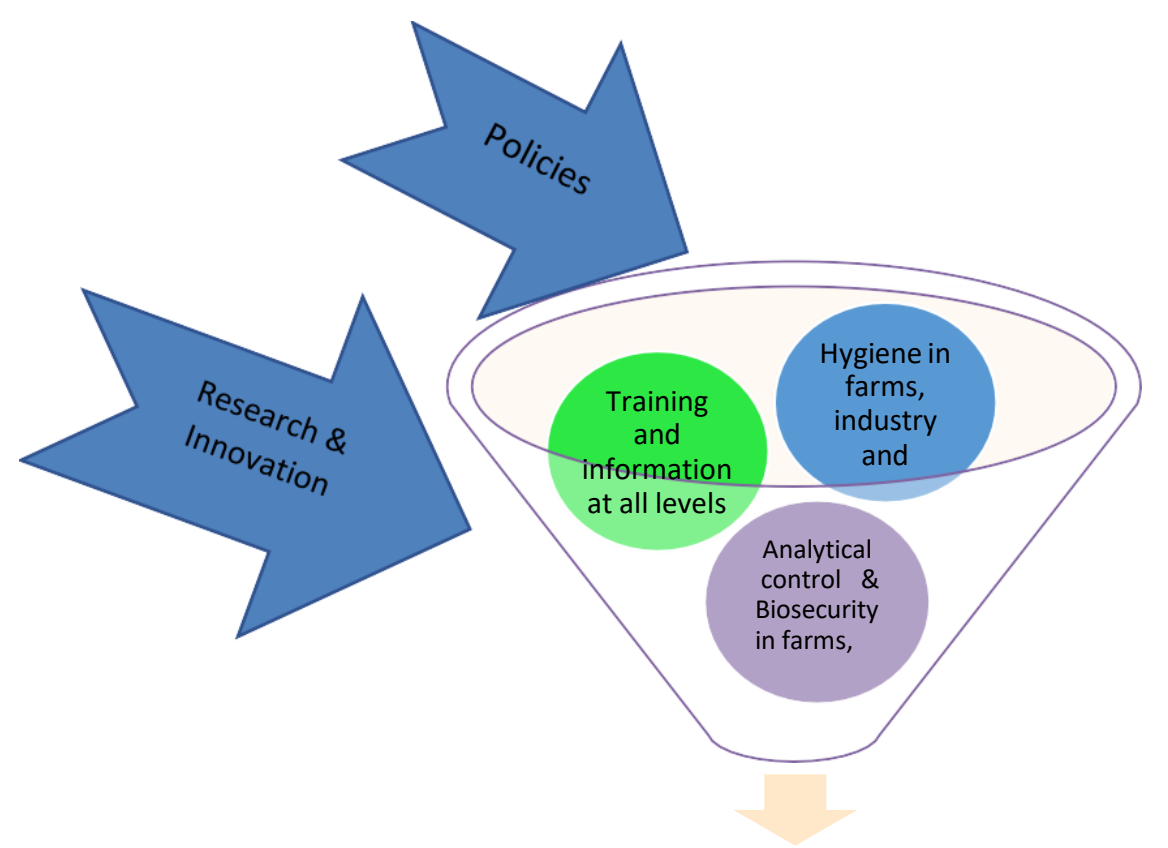

\section{Fit together}

Fig 2: Conjugate all the strategies to fight against Campylobacter Global Health Issue.

\section{Recent interventions and their conclusion}

Multiple strategies have been implemented to reduce Campylobacter colonization in the food chain. Recently, scientists have started looking at alternatives to antibiotics to mitigate multidrug-resistant Campylobacter. Scientists have explored prebiotics as a supplement to prevent colonization in the gut of animals.(Dai et al., 2020) However, the findings were inconsistent. The researchers also moved their focus towards chemical-based antimicrobials such as trisodium phosphate (TSP), peracetic acid (PAA), acidified sodium chlorite (ASC), and cetylpyridinium chloride (CPC). These chemicals are usually applied as spray or surface sanitizers in the poultry farms and the places where broilers are processed.(Johnson et al., 2017) Currently, major investigations are being conducted to improve intervention methods in poultry processing. Processing plants cannot rely on the integrity of cold transportation of food products to retailers and therefore, must prioritize advancements on antimicrobial interventions. Many factors are driving industrial changes but one of the most prominent factors is pressure by public demand for safer mechanisms.(MacRitchie et al., 2014) People are not only exploring alternative methods 
but also looking at novel methods to kill these microbes such as electrostatic spraying, cold plasma treatment, and bacteriophages-based methods.(Soro et al., 2020)

Campylobacter is the most notorious bacterium accounting for its rapid spread and colonization in animals and humans through food and excreta. There is a debate regarding the administration of antimicrobial regimen in the management of uncomplicated Campylobacter infections since it is usually self-limited and most patient recovers without administration of antibiotics. Antibiotics should be reserved for cases of $C$. jejuni with indicated risk for severe illness with systemic manifestation (Ruiz-Palacios, 2007). According to the CDC guidelines, antibiotics should be reserved for elderly people (65 years or older), pregnant women, and immunocompromised. The government bodies need to pay more attention to the interventions of Campylobacter spread. Better guidelines and novel intervention might give a new perspective and a better chance to mitigate Campylobacter.

\section{References}

Asuming-Bediako, N., Kunadu, A. P. H., Abraham, S., \& Habib, I. (2019). Campylobacter at the human-food interface: the African perspective. In Pathogens (Vol. 8, Issue 2). MDPIAG. https://doi.org/10.3390/pathogens8020087

Avrain, L., Vernozy-Rozand, C., \& Kempf, I. (2004). Evidence for natural horizontal transfer of tetO gene between Campylobacter jejuni strains in chickens. Journal of Applied Microbiology, 97(1), 134-140. https://doi.org/10.1111/j.1365-2672.2004.02306.x

Backert, S., Boehm, M., Wessler, S., \& Tegtmeyer, N. (2013). Transmigration route of Campylobacter jejuni across polarized intestinal epithelial cells: Paracellular, transcellular or both? In Cell Communication and Signaling (Vol. 11, Issue 1, p. 72). BioMed Central. https://doi.org/10.1186/1478-811X-11-72

Bi, P., Cameron, A. S., Zhang, Y., \& Parton, K. A. (2008). Weather and notified Campylobacter infections in temperate and sub-tropical regions of Australia: An ecological study. Journal of Infection, 57(4), 317-323. https://doi.org/10.1016/j.jinf.2008.08.004

Biswas, D., Hannon, S. J., Townsend, H. G. G., Potter, A., \& Allan, B. J. (2011). Genes coding for virulence determinants of Campylobacter jejuni in human clinical and cattle isolates 
from Alberta, Canada, and their potential role in colonization of poultry. International Microbiology, 14(1), 25-32. https://doi.org/10.2436/20.1501.01.132

Bolton, D. J. (2015). Campylobacter virulence and survival factors. In Food Microbiology (Vol. 48, pp. 99-108). Academic Press. https://doi.org/10.1016/j.fm.2014.11.017

Buchanan, C. J., Webb, A. L., Mutschall, S. K., Kruczkiewicz, P., Barker, D. O. R., Hetman, B. M., Gannon, V. P. J., Abbott, D. W., Thomas, J. E., Inglis, G. D., \& Taboada, E. N. (2017). A Genome-Wide Association Study to Identify Diagnostic Markers for Human Pathogenic Campylobacter jejuni Strains. Frontiers in Microbiology, 8(JUN), 1224. https://doi.org/10.3389/fmicb.2017.01224

Callicott, K. A., Haroardóttir, H., Georgsson, F., Reiersen, J., Frioriksdóttir, V., Gunnarsson, E., Michel, P., Bisaillon, J. R., Kristinsson, K. G., Briem, H., Hiett, K. L., Needleman, D. S., \& Stern, N. J. (2008). Broiler Campylobacter contamination and human campylobacteriosis in Iceland. Applied and Environmental Microbiology, 74(21), 64836494. https://doi.org/10.1128/AEM.01129-08

Campylobacter Infections: Background, Pathophysiology, Epidemiology. (n.d.). Retrieved April 2, 2021, from https://emedicine.medscape.com/article/213720-overview

Campylobacteriosis - Annual Epidemiological Report 2016 [2014 data]. (n.d.). Retrieved April 2, 2021, from https://www.ecdc.europa.eu/en/publications-data/campylobacteriosisannual-epidemiological-report-2016-2014-data

Chen, H., Zha, J., Zhong, J. M., Chen, Y., Yu, X. Y., \& Xie, J. H. (2019). Clinical features of campylobacter-associated benign convulsions with mild gastroenteritis compared with rotavirus convulsions. Seizure, 70, 20-24.

https://doi.org/10.1016/j.seizure.2019.06.010

Costa, D., \& Iraola, G. (2019). Pathogenomics of emerging Campylobacter species. Clinical Microbiology Reviews, 32(4). https://doi.org/10.1128/CMR.00072-18

Dai, L., Sahin, O., Grover, M., \& Zhang, Q. (2020). New and alternative strategies for the prevention, control, and treatment of antibiotic-resistant Campylobacter. In Translational Research (Vol. 223, pp. 76-88). Mosby Inc. https://doi.org/10.1016/j.trsl.2020.04.009 
Di Giannatale, E., Calistri, P., Di Donato, G., Decastelli, L., Goffredo, E., Adriano, D., Mancini, M. E., Galleggiante, A., Neri, D., Antoci, S., Marfoglia, C., Marotta, F., Nuvoloni, R., \& Migliorati, G. (2019). Thermotolerant Campylobacter spp. in chicken and bovine meat in Italy: Prevalence, level of contamination and molecular characterization of isolates. PLOS ONE, 14(12), e0225957. https://doi.org/10.1371/journal.pone.0225957

Elhadidy, M., Ali, M. M., El-Shibiny, A., Miller, W. G., Elkhatib, W. F., Botteldoorn, N., \& Dierick, K. (2020). Antimicrobial resistance patterns and molecular resistance markers of Campylobacter jejuni isolates from human diarrheal cases. PLOS ONE, 15(1), e0227833. https://doi.org/10.1371/journal.pone.0227833

Food Safety Authority, E., Boelaert, F., Stoicescu, A., Amore, G., Messens, W., Hempen, M., Rizzi, V., Antoniou, S.-E., Baldinelli, F., Dorbek-Kolin, E., Van der Stede, Y., ECDC staff members Taina Niskanen, the, Haussig, J., Kaczmarek, M., Gomes Dias, J., Barco, L., Mancin, M., Mantovani, C., Sardella, A., ... Altieri, I. (2021). The European Union One Health 2019 Zoonoses Report. EFSA Journal, 19(2), 6406.

https://doi.org/10.2903/j.efsa.2021.6406

Frirdich, E., Biboy, J., Huynh, S., Parker, C. T., Vollmer, W., \& Gaynor, E. C. (2017).

Morphology heterogeneity within a Campylobacter jejuni helical population: the use of calcofluor white to generate rod-shaped C. jejuni 81-176 clones and the genetic determinants responsible for differences in morphology within 11168 strains. Molecular Microbiology, 104(6), 948-971. https://doi.org/10.1111/mmi.13672

Gharst, G., Oyarzabal, O. A., \& Hussain, S. K. (2013). Review of current methodologies to isolate and identify Campylobacter spp. from foods. Journal of Microbiological Methods, 95(1), 84-92. https://doi.org/10.1016/j.mimet.2013.07.014

Gwimi, P. B., Faleke, O. O., Salihu, M. D., Magaji, A. A., Abubakar, M. B., Nwankwo, I. O., \& Ibitoye, E. B. (2015). Prevalence of Campylobacter species in fecal samples of pigs and humans from Zuru Kebbi State, Nigeria. In International Journal of One Health Available at www.onehealthjournal.org (Vol. 1). www.onehealthjournal.org/Vol.1/1.pdf

Hald, B., Skov, M. N., Nielsen, E. M., Rahbek, C., Madsen, J. J., Wainø, M., Chriél, M., Nordentoft, S., Baggesen, D. L., \& Madsen, M. (2016). Campylobacter jejuni and 
Campylobacter coli in wild birds on Danish livestock farms. Acta Veterinaria Scandinavica, 58(1), 11. https://doi.org/10.1186/s13028-016-0192-9

Havelaar, A. H., Kirk, M. D., Torgerson, P. R., Gibb, H. J., Hald, T., Lake, R. J., Praet, N., Bellinger, D. C., de Silva, N. R., Gargouri, N., Speybroeck, N., Cawthorne, A., Mathers, C., Stein, C., Angulo, F. J., \& Devleesschauwer, B. (2015). World Health Organization Global Estimates and Regional Comparisons of the Burden of Foodborne Disease in 2010. PLOS Medicine, 12(12), e1001923. https://doi.org/10.1371/journal.pmed.1001923

Igwaran, A., \& Okoh, A. I. (2019). Human campylobacteriosis: A public health concern of global importance. In Heliyon (Vol. 5, Issue 11, p. e02814). Elsevier Ltd. https://doi.org/10.1016/j.heliyon.2019.e02814

Information for Health Professionals / Campylobacter / CDC. (n.d.). Retrieved April 2, 2021, from https://www.cdc.gov/campylobacter/technical.html

Johnson, T. J., Shank, J. M., \& Johnson, J. G. (2017). Current and potential treatments for reducing Campylobacter colonization in animal hosts and disease in humans. In Frontiers in Microbiology (Vol. 8, Issue MAR). Frontiers Research Foundation. https://doi.org/10.3389/fmicb.2017.00487

Kaakoush, N. O., Castaño-Rodríguez, N., Mitchell, H. M., \& Man, S. M. (2015). Global epidemiology of campylobacter infection. Clinical Microbiology Reviews, 28(3), 687720.

Kenyon, J., Inns, T., Aird, H., Swift, C., Astbury, J., Forester, E., \& Decraene, V. (2020). Campylobacter outbreak associated with raw drinking milk, North West England, 2016. Epidemiology and Infection, 148.

Kuhn, K. G., Nygård, K. M., Guzman-Herrador, B., Sunde, L. S., Rimhanen-Finne, R., Trönnberg, L., Jepsen, M. R., Ruuhela, R., Wong, W. K., \& Ethelberg, S. (2020). Campylobacter infections expected to increase due to climate change in Northern Europe. Scientific Reports, 10(1), 13874. https://doi.org/10.1038/s41598-020-70593-y

Kumar B, A., Thankappan, B., Jayaraman, A., \& Gupta, A. (2021). Evaluation of Antibiotic Tolerance in Pseudomonas aeruginosa for Aminoglycosides and Its Predicted Gene Regulations through In-Silico Transcriptomic Analysis. Microbiology Research, 12(3), 
630-645. doi:10.3390/microbiolres12030045

Liu, F., Ma, R., Wang, Y., \& Zhang, L. (2018). The clinical importance of campylobacter concisus and other human hosted Campylobacter species. In Frontiers in Cellular and Infection Microbiology (Vol. 8, Issue JUL, p. 243). Frontiers Media S.A. 
https://doi.org/10.3389/fcimb.2018.00243

MacRitchie, L. A., Hunter, C. J., \& Strachan, N. J. C. (2014). Consumer acceptability of interventions to reduce Campylobacter in the poultry food chain. Food Control, 35(1), 260-266. https://doi.org/10.1016/j.foodcont.2013.06.005

Mearelli, F., Casarsa, C., Breglia, A., \& Biolo, G. (2017). Septic Shock with multi organ failure due to fluoroquinolones resistant Campylobacter Jejuni. American Journal of Case Reports, 18, 972-974. https://doi.org/10.12659/AJCR.904337

Meyrieux, V., Monneret, G., Lepape, A., Chomarat, M., \& Banssillon, V. (1996). Fatal septic shock with multiple organ failure due to Campylobacter jejuni. Clinical Infectious Diseases, 22(1), 183-184. https://doi.org/10.1093/clinids/22.1.183

Newell, D. G., \& Fearnley, C. (2003). Sources of Campylobacter colonization in broiler chickens. In Applied and Environmental Microbiology (Vol. 69, Issue 8, pp. 4343-4351). American Society for Microbiology. https://doi.org/10.1128/AEM.69.8.4343-4351.2003

Pascoe, B., Schiaffino, F., Murray, S., Méric, G., Bayliss, S. C., Hitchings, M. D., Mourkas, E., Calland, J. K., Burga, R., Yori, P. P., Jolley, K. A., Cooper, K. K., Parker, C. T., Olortegui, M. P., Kosek, M. N., \& Sheppard, S. K. (2020). Genomic epidemiology of campylobacter jejuni associated with asymptomatic pediatric infection in the peruvian amazon. PLoS Neglected Tropical Diseases, 14(8), 1-19. https://doi.org/10.1371/journal.pntd.0008533

Ramos, A. P., Leonhard, S. E., Halstead, S. K., Cuba, M. A., Castañeda, C. C., Dioses, J. A., Tipismana, M. A., Abanto, J. T., Llanos, A., Gourlay, D., Grogl, M., Ramos, M., Rojas, J. D., Meza, R., Puiu, D., Sherman, R. M., Salzberg, S. L., Simner, P. J., Willison, H. J., ... Pardo, C. A. (2021). Guillain-Barré Syndrome Outbreak in Peru 2019 Associated With Campylobacter jejuni Infection. Neurology(R) Neuroimmunology \& Neuroinflammation, 8(2). https://doi.org/10.1212/NXI.0000000000000952

Ruiz-Palacios, G. M. (2007). The health burden of Campylobacter infection and the impact of antimicrobial resistance: Playing chicken. In Clinical Infectious Diseases (Vol. 44, Issue 5, pp. 701-703). https://doi.org/10.1086/509936

Scallan, E., Hoekstra, R. M., Mahon, B. E., Jones, T. F., \& Griffin, P. M. (2015). An assessment 
of the human health impact of seven leading foodborne pathogens in the United States using disability adjusted life years. Epidemiology and Infection, 143(13), 2795-2804. https://doi.org/10.1017/S0950268814003185

Schiaffino, F., Colston, J. M., Paredes-Olortegui, M., François, R., Pisanic, N., Burga, R., Peñataro-Yori, P., \& Kosek, M. N. (2019). Antibiotic resistance of Campylobacter species in a pediatric cohort study. Antimicrobial Agents and Chemotherapy, 63(2). https://doi.org/10.1128/AAC.01911-18

Soro, A. B., Whyte, P., Bolton, D. J., \& Tiwari, B. K. (2020). Strategies and novel technologies to control Campylobacter in the poultry chain: A review. Comprehensive Reviews in Food Science and Food Safety, 19(4), 1353-1377. https://doi.org/10.1111/15414337.12544

Tam, C. C., O’Brien, S. J., Adak, G. K., Meakins, S. M., \& Frost, J. A. (2003). Campylobacter coli - An important foodborne pathogen. Journal of Infection, 47(1), 28-32. https://doi.org/10.1016/S0163-4453(03)00042-2

Tresse, O., Alvarez-Ordóñez, A., \& Connerton, I. F. (2017). Editorial: About the foodborne pathogen Campylobacter. In Frontiers in Microbiology (Vol. 8, Issue OCT). Frontiers Media S.A. https://doi.org/10.3389/fmicb.2017.01908

Truccollo, B., Whyte, P., Burgess, C., \& Bolton, D. (2021). Genetic characterisation of a subset of Campylobacter jejuni isolates from clinical and poultry sources in Ireland. PLOS ONE, 16(3), e0246843. https://doi.org/10.1371/journal.pone.0246843

Wieczorek, K., Wolkowicz, T., \& Osek, J. (2018). Antimicrobial resistance and virulenceassociated traits of Campylobacter jejuni isolated from poultry food chain and humans with diarrhea. Frontiers in Microbiology, 9(JUL), 1508. https://doi.org/10.3389/fmicb.2018.01508

Yang, Y., Feye, K. M., Shi, Z., Pavlidis, H. O., Kogut, M., J. Ashworth, A., \& Ricke, S. C. (2019). A Historical Review on Antibiotic Resistance of Foodborne Campylobacter. Frontiers in Microbiology, 10, 1509. https://doi.org/10.3389/fmicb.2019.01509 